\title{
Learning Oceanography from a Computer Simulation Compared with Direct Experience at Sea
}

\author{
William Winn, ${ }^{1}$ Frederick Stahr, ${ }^{2}$ Christian Sarason, ${ }^{2}$ Ruth Fruland, ${ }^{1}$ \\ Peter Oppenheimer, ${ }^{3}$ Yen-Ling Lee ${ }^{1}$ \\ ${ }^{1}$ College of Education, Box 353600, 412 Miller, University of Washington, \\ Seattle, Washington 98195 \\ ${ }^{2}$ Ocean Inquiry Project, Seattle, Washington \\ ${ }^{3}$ Human Interface Technology Laboratory, University of Washington, Seattle, Washington
}

\section{Received 23 March 2004; Accepted 9 February 2005}

\begin{abstract}
Considerable research has compared how students learn science from computer simulations with how they learn from "traditional" classes. Little research has compared how students learn science from computer simulations with how they learn from direct experience in the real environment on which the simulations are based. This study compared two college classes studying introductory oceanography. One class learned using an interactive computer simulation based on a dynamic, three-dimensional model of physical oceanography. The other class learned by spending a day on a research ship using scientific tools and instruments to measure physical properties of the ocean directly. In classes preceding and following the simulation or field experience, students performed the same exercises regarding currents and salinity, had the same instructor presentations, and did the same homework. The study found that the field experience helped contextualize learning for students with little prior experience of the ocean while the simulation made it easier for students to connect what they learned from it to other content they learned in class. These and other findings shed light on what computer simulations can and cannot help students learn, and what concepts are best learned in the real environment. (C) 2005 Wiley Periodicals, Inc. J Res Sci Teach 00: 1-18, 2005
\end{abstract}

The educational role of computers has expanded from just providing drills that support rote memorization (Steffe \& Olive, 2002), tutorials that support the development of concepts (Raghavan \& Katz, 1989; Rowley \& Meyer, 2003-2004), and data-gathering activities that

\footnotetext{
Contract grant sponsor: National Science Foundation's Research on Educational Policy and Practice Program; Contract grant number: REC-9873620; Contract grant sponsor: Office of Naval Research's National Oceans Partnership Program; Contract grant number: N00014-02-1-0502.

Correspondence to: W. Winn; E-mail: billwinn@u.washington.edu

DOI 10.1002/tea.20097

Published online in Wiley InterScience (www.interscience.wiley.com).
} 
support knowledge construction (Linn, Songer, \& Eylon, 1994). Now, in addition, computers can provide complete interactive model-based environments, comprising both static and dynamic phenomena, which can promote conceptual change in new and potentially more effective ways (Raghavan, Sartoris, \& Glaser, 1998; Resnick, 1994; Stratford, 1997). These simulations allow students to observe phenomena and do activities, albeit vicariously, that they could hitherto only do in the real world. They range from fully "immersive" learning environments, created with virtual reality technology, to a variety of dynamic, two- and three-dimensional desktop environments (Dede, Salzman, Loftin, \& Ash, 2000).

The assumption that students learn some things better through direct experience has a long history. For example, Dewey (1990) made the point that a map is an abstraction of a journey. Successful education in geography requires that students have direct experience of the journey as well as experience of the map. By analogy, computer simulations are "maps" (abstractions) of the real world. We might therefore expect that the closer the simulated experience is to the real-world experience, the better the students will learn. Indeed, research has already shown that the more students feel "present" in a computer-created environment-believing that they are in the simulated world, not the real one (Witmer \& Singer, 1998; Zeltzer, 1991) — the more they learn (Winn et al., 2002). This assumption is consistent with current thinking about the value of situating learning activities in settings that are authentic so that learning can be cognitively and socially contextualized (Brown, Collins, \& Duguid, 1989; Lave \& Wenger, 1991).

Authentic activity does not, on its own, teach general principles. Likewise, simulations that strive primarily to re-create real-world experiences often do not directly help students discover general principles. The usefulness of simulating real-world experience without teaching students general principles directly has been challenged (Merrill, 1992) as impeding rather than supporting students' ability to generalize what they have learned and apply it to new contexts. In a similar vein, Caird (1996) observed that placing a premium on fidelity to reality in simulations can hide powerful abstractions that students must learn behind a plethora of detail that may serve to obscure rather than provide insights. Alessi (1988) pointed out that this is a particular problem for beginning students, like the ones who took part in this study. Scientific models limit the number of variables and simplify the complexity of systems so that patterns of behavior and causal relationships may be more easily discernible. Therefore, even though authentic direct experience has a place in learning, the case can also be made for the value of learning activities that provide less-than-realistic experiences. In order for students to understand physical oceanography, they must have the opportunity to learn general principles as well as facts and details about how the ocean works.

The purpose of this study was to compare what a class of oceanography students learned through direct experience by spending a day on a research vessel, during which they gathered and analyzed data using oceanographic research tools, with what a second class of students learned from a computer simulation that allowed them to gather and analyze the same data as the students at sea. Among other things, the study examined how the effects of context affected conceptual change and generalization. Data from the study were expected to provide information about how students learn science differently (if at all) in simulated and natural environments.

Kolb's experiential learning theory (Kolb, 1984; Kolb, Boyatzis, \& Mainemelis, 2001) provides a useful framework within which to think about how students learn with simulations compared with real-world experiences. Kolb's theory describes four successive learning stages in an iterative cycle, including concrete experiences (sensing and feeling), reflective observations (reflecting), conceptualizations (thinking), and active experimentation (doing). The theory stresses the importance of direct interaction with the environment for both the acquisition and application of experience. It also stresses the intermediate need to develop more abstract 
conceptions from experience and to reflect on them. Kolb's four-stage "cycle" therefore encompasses concrete experiences and observations of them, and the distillation of these into more abstract concepts, whose implications guide subsequent actions that help create new experiences.

Model-based computer simulations, unlike physical simulators such as flight simulators, can never provide complete facsimiles of dynamic real-world behaviors, and are, like the models themselves, imperfect, oversimplified, and unfinished (Meadows, Meadows, Rander, \& Behrens, 1972). However, simplification serves a purpose. Many of the studies reviewed by De Jong and Van Joolingen (1998) and by Bayraktar (2002) suggest that if simulations are designed and used properly, the absence of some aspects of real-world experience can be an advantage. They may even prepare students to better function in authentic tasks subsequently (Zacharia \& Anderson, 2003). A good simulation may therefore teach abstract concepts better than direct experience. This is particularly true when the simulation successfully uses metaphors to show phenomena that have no perceptible presence in the real world. Examples are: (1) when conventional graphical symbol systems are used as analogs for both physical and nonphysical processes (Larkin \& Simon, 1987); (2) when graphical metaphors allow cognition to be "externalized" (Scaife \& Rogers, 1996; Tanimoto, Winn, \& Akers, 2002) for students to observe and manipulate directly, and, most important for this study; (3) when the graphics are animated to show change over time (Price, 2002; Tversky, Morrison, \& Betrancourt, 2002). For these reasons, it was expected that the simulation of ocean processes would be most effective in the second and third ("abstracting" and "reflecting") stages of Kolb's cycle (Ruben, 1999; Soderberg \& Price, 2003). By contrast, doing exercises on a research vessel would provide the direct sensory experiences that a computer simulation cannot, and would be more effective for the first and fourth ("data-gathering" and “experimentation") stages of the cycle (Whitford \& Eisman, 1999).

Kolb's experiential learning framework can be implemented as an instructional strategy by building on tried-and-true methods for bringing about conceptual change in students (Posner, Strike, Hewson, \& Getrzog, 1982; Windschitl \& André, 1998). In this framework, students start by gathering data that cannot be explained by their current conceptions. Next, they think of reasons that account for the discrepancy between their observations and their prior conceptions. Finally, they construct experiments to test their new conceptions. The process continues iteratively until the new conceptions fit with the students' data, or the students give up.

This approach has been used with different degrees of success, with and without computer simulations, in a wide range of science subjects at most grade levels (Linn \& Muilenburg, 1996; Windschitl \& André, 1998). Also, this strategy for changing students' conceptions cannot work without instructional support (Mayer, 2004; Windschitl, 2000), which in this study was provided by the class instructors, teaching assistants, and learning materials, both before, during, and after the real and simulated data collection experience. This study therefore used an instructional strategy that implemented these principles.

\section{Method}

\section{Setting: Puget Sound}

The study focused on students learning about the oceanography of Puget Sound, a fjord and estuary system entirely within the state of Washington, on the shores of which lies Seattle. Puget Sound is a long, narrow, multibranched inlet, running roughly 200 kilometers north to south, that opens into the Straits of Juan de Fuca, an arm of the North Pacific Ocean that separates the United States from Canada. Many rivers flow into it, making the water generally fresher than the open 
ocean, like all estuary systems. However, it also has deep basins, which hold more saline water as do fjord systems. It is surrounded by a population of approximately 3.5 million spread among many cities, but primarily focused in the Seattle-Tacoma metropolitan area.

\section{Students, Courses, and Instructors}

Students in two introductory oceanography classes took part in the study. One class was offered at a community college, the other at a university. Each class had approximately 25 students. The students took part in the study for three sessions of the class, the first and third of which covered identical material, taught by the same instructors, using the same strategies and activities. The difference between the classes occurred during the second session, in which the community college students performed exercises on a field trip aboard a research vessel on Puget Sound (the "Field" class), whereas the university students performed similar exercises using a three-dimensional computer simulation of the same environment, "Virtual Puget Sound" (the "VPS" class).

Because the study worked with intact classes, random assignment of students to treatments was not possible. The two courses used for this study may therefore appear prima facie to be different, but this was not the case. Both courses are entry level and therefore have no prerequisites, nor does either act as a prerequisite for any subsequent course. Both tend to attract nearly identical types of students: those with some interest in the ocean, but with little to no prior knowledge about it, nor necessarily with any intent to continue further study of it. Although the two courses are offered at different types of institution (university and community college), scheduling for the university course is in the evening, which tends to make the student body more similar in age and skill to the community college class. In both cases, students enrolled more from a desire for further education about the material, rather than for any particular programmatic reason, with the possible exception of a need for natural science credits, which is the same for both institutions.

The two courses were of different durations: a 3-day short course at the community college versus a quarter-long offering at the university. However, the instructors, who were both members of the research team (Sarason and Stahr), made the pertinent sections of each class equivalent. For the university students, the section on Puget Sound was the first module they went through during the quarter so that they started with the same entry knowledge as the community college students. The duration of instruction was the same, in both cases delivered in 2.5-hour segments. Both classes were introduced to the study, pretested, and instructed in the first session; provided with the experience, either at sea or in the computer lab, during the second session; and instructed again, then posttested during the third. The instructors, materials, presentations, activities, and curricula were the same for both, as were the pre- and posttests. The only difference between the classes beyond the different experiences during the second session was the overall timing. The university students completed all three sessions of the study within 1 week, whereas the community college students needed 3 weeks due to a delay in the at-sea experience because of bad weather.

\section{Materials}

"Virtual Puget Sound" (VPS) is a dynamic three-dimensional visualization of two major oceanographic parameters - water movement and salinity — set within the bathymetry (shape of the land underwater) of Puget Sound. The oceanographic data visualized by VPS are generated by an adaptation of the Princeton Oceanographic Model to Puget Sound (Blumberg \& Mellor, 1987; Warner, Kawase, \& Newton, 2002). VPS was originally developed for use with immersive virtual 
reality (VR) technology, specifically a head-mounted display, head-tracking, and a hand-held controller interface (Winn et al., 2002). Because this study was designed in part to examine what it is feasible for students to learn in regular classes, VPS was ported to a standard desktop computer (Windows OS). In contrast to the fully immersive VPS, in the desktop version, the viewer engages in the visualization through a standard interface comprising a monitor, keyboard, and three-button mouse controlling the simulation through dialog boxes and pop-up menus.

One limitation of VPS, at present, is that the student can manipulate only a limited number of the independent variables that control the simulation. These are: whether the tides follow a neap or spring profile; whether or not time runs and the rate at which it passes; when and where particle tracers are released into the water to observe the current; where measurements of ocean properties are made; and some of the ways in which data are displayed. The student cannot, for example, change the nature of the bathymetry, the salinity of the water, or the speed of the currents.

VPS provides salinity and horizontal velocity data at 9 depths on a model grid, $900 \times 600$ meters, covering the whole Puget Sound (approximately 60 kilometers east/west by 200 kilometers north/ south). Data are presented at 30-minute intervals for a 24-hour period covering two high and two low tides, for a total of 48 data points per day. Because tides in Puget Sound are semidiurnal, there are large differences between spring and neap tidal amplitudes. Therefore, for this study, two different data files were used, one representing a day with a spring tidal phase (large variation between high and low tides) and one with a neap tidal phase (smaller variation) to highlight the differences in circulation caused by these weekly variations. The user may consult an animated tide chart. This chart shows a line graph of the height of the water at one point (Seattle) plotted against a 24-hour time-line. When time is running, a vertical line cycles over the graph from left to right, showing the state of the tide at each moment. The duration of a 24-hour tidal cycle is compressed by default into roughly 5 seconds, but the user can start and stop the animation and can control its speed. The animation loops continuously through the same data-at the end of each cycle, and it starts the same cycle over again. This constraint arises partly from the size of the data files and limited computer memory. Although VPS does not provide a perfect representation of the natural tidal cycle, it was adequate for the purposes of this study.

VPS allows users to fly over, swim within, and look at Puget Sound from any viewpoint, using the mouse. The user also controls what is visible or not; that is, the tide chart, the current vectors, the particles, and various parts of the terrain. The land topography and basin bathymetry are shown with a tenfold vertical exaggeration, making it easier to move without bumping into boundaries and to see the effects of bathymetry on circulation.

Salinity, current speed, and direction can be measured by the user at any location and at any depth using on-screen panels that provide digital readouts. These are equivalent in function and in type of information to that provided by the oceanographic instruments used by the students in the "Field" class. In addition, current speed and direction can be shown as animated arrows (vectors), indicating speed with length. They are seen at every other model node and for each depth layer, thus indicating differences in currents from surface to bottom at any given time step. Water movement can also be shown through the movement of particle tracers that can be released at any location or depth, one per half-hour time-step. Released particles move in approximately the same way a water parcel would in the Sound. The location and number of particles can be modified, allowing students to create experiments on the flow of water in Puget Sound. Although the animation loops through the same 24 hours of data on a continuous basis, the positions of particles are not reset at the end of each cycle, but start the new cycle from their positions at the end of the previous one. This gives the impression of continuous time for days or weeks, although it is scientifically inaccurate for a period longer than 2 days. To exercise a measure of experimental control in this study, students were limited to what they could do at the particle-release points. 
In addition to numerical values in the data panels, salinity can be shown as a color-coded vertical slice through the water column by using two movable cut-planes that run the full length (north-south) or width (east-west) of the model domain. The color scale indicates salinity from red, the most saline, to green, the least. At any point in the tidal cycle, each cut-plane therefore provides salinity values as a colored surface along its length. When time is running, the animated colors graphically depict salinity changes over time. The user can position the cut-planes by moving vertical and horizontal sliders in a dialog box, guided by a small-scale map.

Only the VPS class (university) used the simulation, whereas the Field class (community college) used instruments to measure the same properties of Puget Sound, although not over the same depth and temporal range. The Field class used a Sea Bird 911+ CTD apparatus to measure water conductivity (used to determine salinity), temperature and depth, as well as other properties, at three locations across the Sound. These were coincident with where the VPS class measured salinity and currents. The CTD was lowered through the full depth of the water column and sampled continuously at $8 \mathrm{~Hz}$. When retrieved, the data were immediately uploaded to a lap-top computer and displayed as graphs plotting each parameter against depth. The temperature and salinity data collected by Field students had high vertical resolution, but limited horizontal resolution. Current speed and direction were measured using an Aanderraa Doppler current meter producing constantly updated readouts on a hand-held unit as it was lowered and raised through the water. Data on current speed and direction were recorded on data sheets during the deployment. The Field students used some other instruments for activities that the VPS students could not perform, such as a Secchi disk to measure water clarity, fine-mesh plankton nets for collecting samples that were viewed using microscopes in a small lab below deck, and navigational equipment to fix the ship's location.

There were obvious differences between the simulation and field experiences. However, each addressed the issue of circulation in Puget Sound. Using VPS, students were able to view more spatially and temporally complete data (model output), as they could fly to anywhere in Puget Sound and stop and reverse time during their experience. In contrast, students in the Field sampled at limited locations and were unable to stop or accelerate time. However, they had a direct sensory connection to the temperature and salinity of the water (my hands are cold; the bow spray tastes salty), and an appreciation of the difficulties of sampling a very complicated system using the standard research tools of the oceanographer.

\section{Procedures}

The study was conducted over three consecutive sessions for each class. The first and third sessions were as identical as possible, although in different classrooms and with slightly different timing and order of exercises. Also, the VPS class went through the whole sequence within 1 week and the Field class had the first and last sessions separated by 2 weeks because bad weather delayed the field trip.

Session 1, both classes. After a brief welcome and introduction of instructors, assistants, and observers, students completed a demographic background questionnaire and a pretest of the study material, described in what follows. Then, the instructors gave an illustrated presentation on the general properties of estuaries, how Puget Sound differs from other estuaries around the country, and how tides act in Puget Sound, as they are the main driving force for the currents and at least partly responsible for the salinity stratification. An exercise followed in which students, working in groups, were asked to describe and interpret annual cycles of temperature, salinity, oxygen, turbidity, and fluorescence data collected from Puget Sound. These data were similar to those collected by the Field class, and served as an introduction to these parameters for both classes. 
Emphasis was placed on drawing inferences from combining parameters, understanding the annual physical and biological cycles in Puget Sound, and looking for changes relative to place and/or time. Data from 2 different days at two different places were used for this exercise. Student groups reported briefly to the class after they had completed their work. Total time was approximately 2.5 hours.

Session 2, Field class. Students spent approximately 6 hours on Puget Sound aboard a 100-ft. research vessel. The weather was cold but calm and did not interfere with any of the exercises. Six groups of students rotated through six activities so everyone did each activity once during the day. Students recorded data for each activity and these were compiled and collated after the cruise. The activities included a CTD cast, a current meter cast, a navigation exercise, a Secchi disk cast, and plankton capture and examination.

Although the cruise lasted longer than the class session during which the VPS students did their comparable exercises ( 6 versus 2.5 hours), the working time spent by the Field class on each exercise was roughly the same due to ship transit time and to the time required for the exercises unrelated to salinity and currents. Time on task was judged similar enough in the two groups not to be of concern in the study.

The activities directly relevant to the study (those parallel to the VPS class) were the CTD cast measuring salinity data and the current meter cast measuring water velocity. The limitations of the field data were that these casts only provided data at three particular points in time and space, and that the current meter only reached the top 30 meters of the water column. The CTD went full depth. The stations that were visited are regular monitoring stations used for time-series research by the Ocean Inquiry Project and other research groups monitoring conditions in Puget Sound. These three locations also provided the first class session's exercise data and were used by the VPS class as well.

Session 2, VPS class. The class met in a computer lab containing nine desktop machines with large monitors running the Virtual Puget Sound (VPS) software. The instructors, with help from other project staff, demonstrated how to use the system. Then the students worked on the exercise. Total time was approximately 2.5 hours.

Like the Field group, students worked in groups of three or four. One group sat at each machine and were given an exercise handout. They were asked first to hypothesize about the relationship between salinity and the tidally forced currents, and then test their hypothesis at each of the same three stations in Puget Sound that the Field students visited. They took salinity and water velocity measurements throughout the water column at two of the stations and on two different tidal phases (spring and neap), from which they were expected to draw conclusions about how salinity and currents are related to each other. Students could use any of VPS's tools to study how such features as the local bathymetry, proximity to shore, proximity to rivers, and phases of tides might play a role. Particle release was restricted to the same three monitoring locations as those visited by the Field group. Students recorded data from the model and drew profiles, plotting relevant ocean properties against depth. From these plots, and the VPS visualizations such as salinity cut-planes, they were to affirm or refute their hypotheses.

Session 3, both classes. The session started with an illustrated presentation on the physical oceanography of Puget Sound, which touched on tidal forcing, mixing, and other controls of circulation and salinity, such as wind and rivers. The instructors made relevant connections to activities students performed using VPS or at sea. This was followed by a case study in the form of a group exercise. Students were provided with Secchi disk data showing a decrease in clarity in Lake Tahoe over a period of several years. During discussion, it was pointed out that, for Lake Tahoe, the Secchi disk measurement can be used to assess water quality and that the data implied a reduction in the health of the lake. They were asked to compare those data with Secchi disk data 
from Puget Sound, which were far more complicated to interpret, and to decide whether this measure of water clarity was a valid measure of water quality and, therefore, the health of Puget Sound. After reporting their decisions to the whole group, the instructor gave a presentation about Puget Sound's biology, touching on photosynthesis, the microbial loop, and the food web, with particular attention to the annual cycle of phytoplankton. The class concluded with posttests.

\section{Instruments and Scoring}

Questionnaire. At the beginning of the first class, students completed a background questionnaire that asked for personal information, including gender, age, how long they had lived close to the ocean, whether or not they had used computers in classes, whether they engaged in water-related activities (e.g., swimming or boating), and whether they had played computer games. The questionnaire was intended to establish equivalence of the VPS and Field groups on potentially confounding factors. Experience with computers in classes and experience with computer games were scored either 1 or 2, with 1 indicating less experience. Experience with water-related activities was scored on a three-point scale.

Pre- and posttests. Objective tests of the course content asked students to rate, on a scale of $1-5$, the truth of 29 statements about Puget Sound. A 5 was chosen if the student believed the statement to be completely true, 1 if completely false. Students also had the option of checking "I don't know" (scored as a 0), reserving the neutral rating, 3, for neither true nor false. The statements were in fact either unambiguously true or false, half the items being true and the others false. The students did not know this, which meant that intermediate ratings between 5 and 1 indicated the degree to which they were less than certain that a statement was true or false. The posttest used the same statements as the pretest, although some were reworded to reverse their truth or falsity, and the order of the items was changed. Students correctly rating a statement either 5 , if true, or 1, if false, received two points, and ratings of 4 for a true statement or 2 for a false one received one point, and ratings other than these, including 0 for "I don't know," received zero points. The statements were written to test knowledge the students were expected to acquire from four sources: (1) the field experience, for example, "Sunlight decreases with depth" (5 items, referred to as "sea" scores); (2) using VPS, for example, "Bathymetry varies with location" (5 items, "simulation" scores); (3) from either the field experience or VPS, for example, "Tides are related to date and time" (7 items, "both" scores); and (4) from the class presentations, for example, "The microbial loop makes nutrients from detritus" (12 items, "class" scores). This resulted in five pretest and five posttest scores-one overall score and four subscores from the four question groups.

Content validity for the pre- and posttests was established by the instructors who developed them. The questions covered all the content that they expected the students to learn and that they had taught in previous versions of the course. The statements to rate were based on questions that had been used in previous offerings of the course from which, in part, grades had been assigned. Reliability coefficients (Cronbach's alpha) were calculated for the complete pre- and posttests and for each of the four subtests. For the complete pretest, alpha $=0.79$ and for the posttest alpha $=0.86$. For the "sea," "simulation," "both," and "class" subscores, alphas for the pretest were $0.69,0.47,0.51$, and 0.81 , respectively, and for the posttest they were $0.76,0.72,0.73$, and 0.76 . Low reliabilities for the "simulation" and "both" subscores on the pretest led these scores to be excluded from all subsequent analyses.

Sketches. As part of the pre- and posttests, students were asked to sketch the general flow of water through Puget Sound from entry, either from the ocean or rivers, to ocean exit. They were given a template, showing a vertical cross-section of the Sound stretching from the open ocean at 


\section{NW - Cross section sketch of Puget Sound - SE}

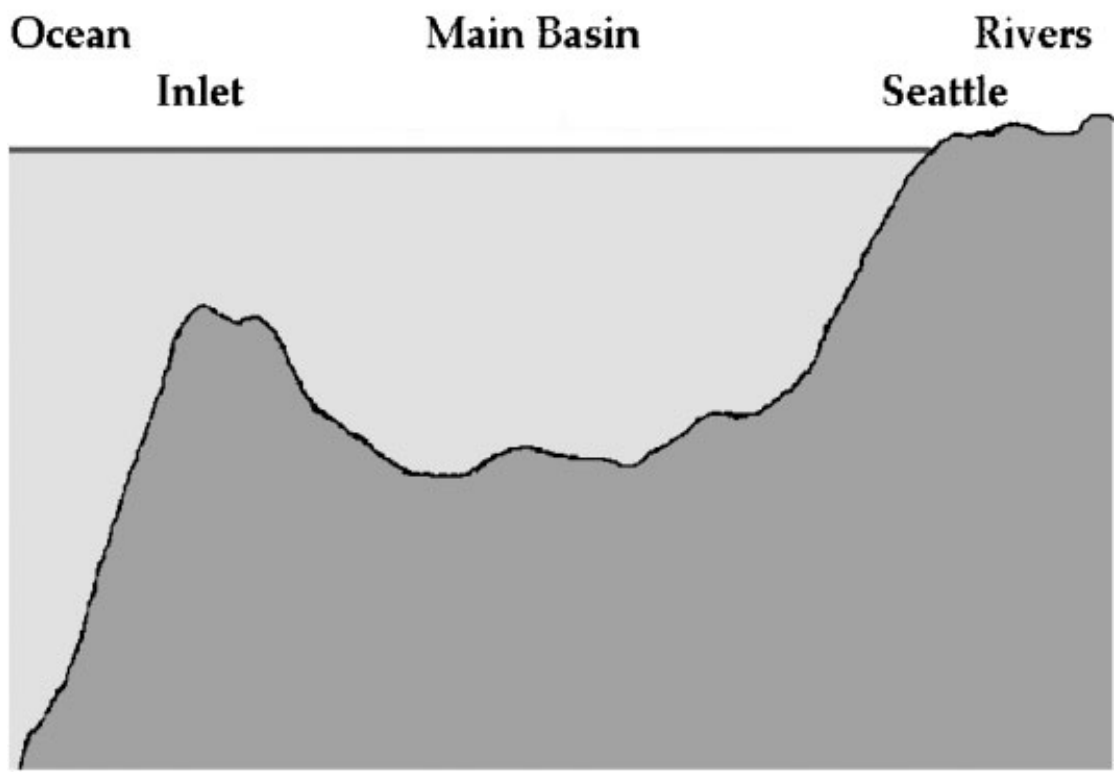

Figure 1. Vertical cross-section of Puget Sound on which students drew water movement.

the Straits of Juan de Fuca to a generic river mouth, on which they were to make their drawing. The template is shown in Figure 1.

The key to understanding how water moves through the Sound is to know that salty, denser ocean water enters at depth, and the fresh, less dense water enters from rivers at the surface. The river water exits along the surface, but entrains some of the ocean water in the process, as well as being mixed through tidally driven flows over rough bottom topography called "sills," near the entrance to the Sound. The purpose of the sketch was to determine whether or not the students understood this vertical circulation pattern. Pre- and post-sketches were scored from 1 to 10 on the basis of a rubric that awarded points for particular features in the drawings.

\section{Results}

Only data from students who participated in all sessions and activities were used in the analysis. This resulted in 21 students (10 females and 11 males) in the VPS class, and 19 students (13 females and 6 males) in the Field class. A nonsignificant chi-square established the equivalence of the groups for gender. The mean age of the VPS group was 24.24 years, with a standard deviation (SD) of 7.05 years, whereas the Field group had a mean age of 27.26 years, with an SD of 10.19 years. Students in the VPS group had lived close to the ocean for a mean of 15.95 years $(\mathrm{SD}=9.13)$, and those in the Field group a mean of 14.00 years $(\mathrm{SD}=13.61) . T$-tests showed neither difference was statistically significant.

Chi-square analysis was performed on the remaining data collected from the initial questionnaire to assess the equivalence of the VPS and Field groups. These data were: where students lived; the level of their experience with water-related activities; where they did these activities; the number of ocean-related courses they had taken; experience with computer-based 
instruction; and whether they played computer games. In all cases but one, the chi-square was not significant, meaning that the groups were equivalent.

The single exception was the level of students' experience with water-related activities. These were assessed by asking students to check boxes for swimming, power-boating, sailing, fishing, surfing, diving, riding ferries, and other, with a space to list what the other activities were. Because level of water activity was now to be used as a grouping variable, students were placed into one of three groups. Students checking one box or none were identified as having the least experience, students checking three or more as having most, and those checking two or three as having an intermediate level of experience. The groups were formed this way so that each group contained roughly the same number of students. Students in the VPS group had engaged in more of these activities than the students in the Field group, chi-square $(2)=6.49, p<0.05$. Previous research with an earlier version of VPS showed that engaging in water-related activities increased what students learned from the simulation (Windschitl \& Winn, 2000). To avoid confounding the data due to this factor, a "Water activity" factor was included in all subsequent analyses. This called for a $2 \times 3$ factorial design, with "Group" and "Water activity" as the two factors. The two levels of Group were VPS and Field. The three levels of Water activity were increasing degrees of engagement in water-related activities.

$T$-tests for repeated measures were used to compare overall pretest and posttest scores as well as the "sea" and "class" subscores created from the question groups outlined earlier. The pre- and posttest scores for the accuracy of the sketches were also compared. The means and SDs for these scores are shown in Tables 1 and 2. In all cases, the posttest scores were significantly higher than the pretest scores (all $p$ 's $<0.001$ ). The "simulation" and "both" scores were not analyzed because pretest reliability was low.

A $2 \times 3$ analysis of variance (ANOVA) was applied first to the overall pretest scores. There were no significant main effects for Group or Water activity, or for the interactions. ANOVA applied to the overall posttest scores showed a significant main effect for Water activity, $F(2,34)=4.61, p<0.05$. Students reporting more water-related experience scored higher than those reporting less. The main effect for Group and the interaction between Group and Water activity were not significant.

ANOVA applied separately to the two reliable pretest subscores, "sea" and "class," showed no main effects and no interactions. ANOVA applied separately to the four posttest subscores gave the following results. For the posttest "simulation" score, there were no significant main effects or interaction. For the posttest "sea" score, the interaction of Group and Water activity was significant, $F(2,34)=3.50, p<0.05$. Examination of the means of the posttest "sea" score,

Table 1

Pre- and posttest means and standard deviations for VPS and Field groups

\begin{tabular}{|c|c|c|c|c|}
\hline \multirow[b]{3}{*}{ Test } & \multicolumn{4}{|c|}{ Occasion and Group } \\
\hline & \multicolumn{2}{|c|}{ Pretest } & \multicolumn{2}{|c|}{ Posttest } \\
\hline & VPS & Field & VPS & Field \\
\hline Sea & $6.62(2.78)$ & $5.89(3.07)$ & $9.05(1.63)$ & $9.16(1.35)$ \\
\hline Simulation & & & $8.76(1.51)$ & $8.58(2.29)$ \\
\hline Both & & & $12.28(2.36)$ & $12.11(2.38)$ \\
\hline Class & $10.00(5.59)$ & $9.63(6.00)$ & $20.19(3.71)$ & $17.56(4.61)$ \\
\hline Total test & $28.24(12.36)$ & $27.21(12.35)$ & $52.38(7.05)$ & $48.95(8.42)$ \\
\hline Sketch & $3.43(1.21)$ & $2.74(1.85)$ & $5.67(1.49)$ & $4.62(1.07)$ \\
\hline
\end{tabular}

Note. Pretest "Simulation" and "Both" scores are not included in this and subsequent tables because of their low reliability. 
Table 2

Pre- and posttest means and standard deviations broken down by water-related activity

\begin{tabular}{|c|c|c|c|c|c|c|}
\hline \multirow[b]{3}{*}{ Test } & \multicolumn{6}{|c|}{ Occasion and Level of Activity } \\
\hline & \multicolumn{3}{|c|}{ Pretest activity } & \multicolumn{3}{|c|}{ Posttest activity } \\
\hline & 1 & 2 & 3 & 1 & 2 & 3 \\
\hline & $5.25(3.33)$ & $6.47(2.83)$ & $6.59(2.85)$ & 8.25 (1.67) & $9.20(1.66)$ & $9.41(1.17)$ \\
\hline Simulation & & & & $8.00(3.38)$ & $8.73(1.28)$ & 8.94 (1.43) \\
\hline Both & & & & $11.25(2.66)$ & $12.13(2.90)$ & $12.82(1.42)$ \\
\hline Class & $7.63(4.34)$ & $9.73(5.34)$ & $10.94(1.59)$ & $14.88(4.45)$ & $19.13(3.42)$ & $20.65(3.90)$ \\
\hline Total test & 23.38 (11.76) & $26.73(11.12)$ & $30.71(13.22)$ & $44.13(10.00)$ & $51.00(6.80)$ & $53.65(5.84)$ \\
\hline Sketch & $2.38(1.92)$ & $3.20(1.32)$ & $3.35(1.50)$ & $4.12(1.13)$ & $5.33(1.54)$ & $5.53(1.18)$ \\
\hline
\end{tabular}

broken down by Group and Water activity, showed that Field students reporting little water-related activity outperformed VPS students reporting little water-related activity. The scores for students reporting a high level of water activity in both groups were equivalent. For the posttest "both" scores, there were no significant main effects or interaction. For the posttest "class" scores, the main effect for Group was significant, $F(1,34)=4.59, p<0.05$, with the students in the VPS group scoring higher than those in the Field group. The main effect for Water activity was also significant, $F(2,34)=5.91, p<0.01$, with the students reporting more water activity performing best. The interaction of Group and Water activity was not significant.

ANOVA applied to the pretest sketch scores showed no main effects or interaction. With the posttest sketch scores, a main effect was found for Group, $F(1,34)=7.31, p<0.01$, with the VPS group drawing more accurate sketches than the Field group. A main effect was also found for Water activity, $F(2,34)=3.84, p<0.05$, with students reporting more water-related activity outperforming those reporting less. The interaction of Group and Water activity was not significant. These findings are summarized in Table 3.

The interaction between Group and Water activity for the "sea" posttest subscore was an important finding. It suggested that going into the field compensated for students' lack of prior

Table 3

Summary of main findings

\begin{tabular}{ll}
\hline Comparison & \multicolumn{1}{c}{ Finding } \\
\hline Overall pretest with posttest & Posttest $>$ pretest \\
Sea pretest with posttest & Posttest $>$ pretest \\
Class pretest with posttest & Posttest $>$ pretest \\
Sketch pretest with posttest & Posttest $>$ pretest \\
Field with VPS, all pretests & No significant differences \\
Field with VPS, overall posttest & No significant difference \\
Field with VPS, class posttest & VPS > Field \\
Field with VPS, sketch posttest & VPS > Field \\
Level of water activity, all pretests & No significant differences \\
Level of water activity, overall posttest & More activity $>$ less \\
Level of water activity, class posttest & More activity $>$ less \\
Level of water activity, sketch posttest & More activity > less \\
Group by water activity interaction, sea posttest & Low activity Field $>$ low-activity VPS; \\
& high Field and high VPS, no difference \\
\hline
\end{tabular}

Note. $p<0.05$ for findings shown as different. 
Table 4

Pre-and posttest means and standard deviations by experience using computers to learn

\begin{tabular}{|c|c|c|c|c|}
\hline \multirow[b]{3}{*}{ Test } & \multicolumn{4}{|c|}{ Occasion and Level of Experience } \\
\hline & \multicolumn{2}{|c|}{ Pretest Experience } & \multicolumn{2}{|c|}{ Posttest Experience } \\
\hline & 1 & 2 & 1 & 2 \\
\hline Sea & $6.88(2.33)$ & $5.88(3.22)$ & $9.25(1.24)$ & $9.00(1.67)$ \\
\hline Simulation & & & $8.56(2.48)$ & $8.75(1.45)$ \\
\hline Both & & & $12.19(2.20)$ & $12.29(2.48)$ \\
\hline Class & $8.81(4.74)$ & $10.50(6.30)$ & $18.69(5.02)$ & $19.08(3.90)$ \\
\hline Total test & $27.31(10.75)$ & $28.04(13.31)$ & $50.38(9.54)$ & $51.00(6.66)$ \\
\hline Sketch & $2.88(1.41)$ & $3.25(1.62)$ & $5.00(1.10)$ & $5.29(1.57)$ \\
\hline
\end{tabular}

water-related experience and therefore improved their performance. If this were indeed the case, a similar effect might be expected for students in the VPS group, with VPS compensating for lack of prior experience relevant to working with a computer simulation. The questionnaire had asked whether or not students used computer-assisted learning before, and whether or not they played computer games. Therefore, to test this conjecture, a $2 \times 2$ ANOVA was performed on pre- and posttest scores with Group as one factor and experience with computer-assisted learning ("Computers") as the second factor. A second set of ANOVAs was performed with game-playing ("Games") as the second factor. Support for the conjecture would come from significant interactions of Group with Computers and Group with Games for the "simulation" posttest subscores.

Means and standard deviations for scores broken down by group, computer experience, and game-playing experience are shown in Tables 4 and 5.

ANOVA with Group and Computers produced no significant main effects or interactions for any pre- or posttest scores. ANOVA with Group and Games showed that, for the sketch posttest scores, the main effect for Games was significant, $F(1,36)=5.26, p<0.05$, with students who played games drawing more accurate sketches than those who did not. For Games with the posttest "class" subscores, $F(1,36)=4.82, p<0.05$. Students who played games performed better than those who did not. The interaction of Group and Games for the posttest "class" subscores was also significant, $F(1,36)=4.22, p<0.05$, showing that Field students who did not play computer games scored lower than Field students who did. The posttest "class" scores of VPS students did not differ as a function of whether or not they played computer games. These findings are summarized in Table 6.

Table 5

Pre-and posttest means and standard deviations by experience playing computer games

\begin{tabular}{|c|c|c|c|c|}
\hline \multirow[b]{3}{*}{ Test } & \multicolumn{4}{|c|}{ Occasion and Level of Experience } \\
\hline & \multicolumn{2}{|c|}{ Pretest Experience } & \multicolumn{2}{|c|}{ Posttest Experience } \\
\hline & 1 & 2 & 1 & 2 \\
\hline Sea & $6.00(3.14)$ & $6.48(2.78)$ & $9.06(1.25)$ & $9.13(1.69)$ \\
\hline Simulation & & & $8.58(2.45)$ & $8.74(1.42)$ \\
\hline Both & & & $11.83(2.90)$ & $12.56(1.83)$ \\
\hline Class & $7.94(3.60)$ & $11.22(6.62)$ & $17.41(4.77)$ & $20.02(3.67)$ \\
\hline Total test & $24.41(9.66)$ & $30.22(13.46)$ & $48.65(9.60)$ & $52.30(5.97)$ \\
\hline Sketch & $2.59(1.73)$ & $3.48(1.27)$ & $4.65(0.79)$ & $5.57(1.62)$ \\
\hline
\end{tabular}


Table 6

Summary of findings involving computer and game-playing experience

Comparison Finding

Level of computer use, all posttests

Level of game-playing, class posttest

Level of game-playing, sketch posttest

Group by game-playing interaction, class posttest
No significant differences

More game-playing $>$ less

More game-playing $>$ less

Field high level $>$ Field low level; VPS, no significant difference

Note. $p<0.05$ for findings shown as different.

\section{Discussion}

\section{Summary of Findings}

The study showed no difference in overall learning between students who used the VPS simulation and those who studied the same material in the field. There were differences, however, when the extent of students' water-related activities before the study was taken into account. Also, differences between the groups were found for types of knowledge best learned from one or the other experience, or only from the class presentations. Regardless of group or types of knowledge tested, students who reported a high level of personal experience in water-related activities scored higher on the posttest than students who reported a minimal level of participation in water-related activities. Students in the Field group, with less prior engagement in water-related activities, performed better on questions that assessed knowledge obtained in the field than students with similarly limited experience who worked with the simulation. There was no difference in fieldderived knowledge for students in either group who had higher prior experience with the ocean.

Students who worked with the simulation performed better than students who worked in the field on questions testing knowledge best obtained in class. The VPS group also drew better sketches of the circulation patterns in Puget Sound. Independent of group, students with more experience with the ocean performed better on questions assessing knowledge obtained in class, and drew better circulation sketches, than those with less experience.

Experience playing computer games paralleled the findings for experience with water-related activities, but with less pronounced effects. Regardless of group, students who reported playing computer games scored better on questions assessing knowledge learned in class than those who reported less experience with games. Game players also drew more accurate sketches of water circulation. Finally, game players who worked in the field performed better on questions about material learned in class than non-game-playing field students. Game-playing did not affect the performance on questions about material learned in class by students who used VPS.

The following discussion focuses on three aspects of these findings: the role of students' prior experience with water-related activities; why students who used the simulation did better on material not taught explicitly in the simulation; and the influence of computer game-playing. This discussion is followed by comments on what sketches can add to what objective tests tell us. The section concludes with suggestions for future research.

\section{Experience With Water-Related Activities}

It is axiomatic that relevant prior knowledge or experience increases student learning. In this study, students who reported participating in water-related activities obtained higher posttest 
scores than those who did not for overall scores, for knowledge learned in class, and for sketches of water circulation. The finding that work in the field improved the performance of students without water-related experience while work with the simulation did not suggests that working in the field compensates for lack of prior experience while working with a simulation does not. There are two possible explanations. First, the more authentic the context, the more students learn, especially if they have not experienced the context before. This conclusion is consistent with other research on the importance of context to learning (Bransford, Brown, \& Cocking, 1999; Brown, Collins, \& Duguid, 1989; Bruer, 1993). An authentic context supports students' understanding content by providing links to what they may already know. Second is the corollary that simulations may not be able to provide a context as authentic as the field experience. Although VPS allows students to interact with visualizations of a highly accurate model of the physical oceanography of Puget Sound, it does not reproduce all the elements of the context, such as the physical experience of being at sea; the experience gained from using real, as opposed to virtual scientific instruments; and the true collaborative nature of work on a research vessel.

At the same time, although VPS has been designed to provide novice learners with intelligible representations, complex scientific visualizations cannot help but include implicit knowledge and conventions that are not instantaneously sensible to students, even with embedded scaffolding (Gordin \& Pea, 1995). The study outcomes may reflect, at least in part, the limited time that students were able to interact with VPS and learn these conventions.

\section{Generalizing From the VPS Simulation}

Although VPS did not compensate for lack of prior relevant experience, it had other advantages. The findings that students using VPS learned more of the material taught in class, and drew better sketches of water circulation than students who worked in the field, suggests that the simulation taught more about the physical processes students studied. There are several possible reasons for this. The first is that the simulation was more extensive in time and space than the field experience. Students who worked in the field visited three locations. Although the students who used VPS went to the same locations to make similar measurements, there was no way they could avoid seeing tidally driven currents over a much wider area-indeed, over the whole Sound. Moreover, VPS provided them with data to observe over an entire tidal cycle-24 hours rather than just three particular times in a 6-hour period. This exposure to the "big picture" could account for their ability to draw more accurate sketches of water movement in the Sound and to answer questions about phenomena taught in class but not observable in the field. However, as noted earlier, the Field students' schedule was disrupted by bad weather that delayed their field experience by 1 week. This meant that VPS students received, over the three class sessions, a more closely spaced set of experiences, which might also account for this finding.

Second, VPS visualizes information in ways that students in the field cannot see. Current vectors and virtual particles, moving through complete tidal cycles, provide information about water movement that can only be inferred indirectly in the field from instruments. Furthermore, the visualizations are explanatory, not just descriptive, because of scaffolding that has been built into VPS. For example, students can observe the animated tide chart at the same time as they watch particles move or vectors oscillate. This allows them to notice, for example, that water moves fastest between high and low tide, not at high (or low) tide, something that students new to oceanography frequently believe (Winn et al., 2002). The ability of such visualizations to help students understand phenomena and solve problems through generalization from observations is well documented (Edelson, Gordin, \& Pea, 1997; Larkin \& Simon, 1987; Tversky, 2001; Tversky et al., 2002). 
Third, because VPS was less realistic than the at-sea experience, it might have been better suited to novice students (Alessi, 1988). Although we did not gather data that suggested the Field students were overwhelmed by the information they encountered in the authentic setting on board the ship, it is possible that the richness and novelty of the experience provided so much new information that they were distracted from the tasks that were designed to help them learn about the ocean. This conjecture requires empirical verification in a future study.

\section{Computer Game-Playing}

The findings relative to experience with computer games were obtained expost facto and must therefore be interpreted with caution. One finding that certainly deserves further study is that game-playing experience did not affect learning material taught in class in the case of VPS students, whereas it did affect what was learned by students who worked in the field. A possible interpretation is that understanding water movement is easier if students possess skills that also help them play computer games. One such skill could be the accurate perception of, interpretation of, and reaction to objects moving dynamically in three dimensions. VPS explicitly models the movement of water for the student, compensating perhaps for lack of these abilities. These skills would give an advantage to students who did not work with VPS.

\section{Sketches}

The movement of water in three dimensions and over time is obviously a spatial phenomenon that can readily be described and assessed using drawings. The sketches students drew were consistent with their performance on objective tests, but also displayed subtleties in their conceptions that were not reflected in scores on the objective tests. Sketches provide a representational modality that can reveal different kinds of information about student understanding than other formats (Winn, 1994). In an unpublished study, for example, middle school students sketched things they had learned about Puget Sound that they were not able to express verbally.

\section{Future Research}

This study established that field work can provide students with authentic contextual experiences that help them understand the environment they are studying. If they already have had such experiences (such as sailing or scuba diving), then the advantage is less pronounced. Our study also provided evidence that, although a simulation may not provide an authentic field experience, it may still provide an authentic model-based experience as scientific visualizations typically do, in which patterns can be observed because of the simplification of data, compression of time and space, and making visible what cannot be seen even during an authentic field experience.

The findings suggest a number of additional research questions. One is whether the fidelity of simulations can and should be increased to provide more authentic learning environments. Research in operational training, such as how to fly airplanes, shows that the higher the fidelity, the better the transfer from the training environment to the real world (Adams, 1957; Caird, 1996). Could a high-fidelity simulation be used to train students to operate research instruments prior to going into the field? Would such high fidelity somehow limit the scope of the conceptual knowledge students could acquire? An important factor in studies designed to answer these questions would be the priorities of operational and conceptual knowledge in classroom 
instruction. Another factor would be the level of expertise of the students (Alessi, 1988). A replication of this study, with more advanced students performing more complex tasks, could test the prediction that students with higher expertise would learn more from the cruise than the novices in this study did.

Another approach would be to look at VPS as a modeling environment, in which the authenticity of the experience depends on how closely it mimics the work of scientists who study computer models of natural phenomena (Edelson, 1998). Scientists use computer models either to further refine their basic understanding of natural processes, such as climate (Stott et al., 2000), or to make predictions about future states, what will happen under particular circumstances, and to guide problem-solving and decision-making (Warner, Kawase, \& Newton, 2002). In this view, VPS and Field experiences complement each other rather than compete for credit as the "best educational strategy." An extension of this idea would be to use VPS as a way to prepare for work at sea. The effectiveness of this use of simulations has been demonstrated by Zacharia and Anderson (2003). A design in which two groups would receive both the field and simulation experience, but in different orders, would overcome the limitation of this study that each group only had one of the two experiences.

The unanticipated finding that experience playing computer games helped students learn about Puget Sound also deserves further study. Clearly, VPS has some properties of computer games that require real-time action by students. Game-playing experience would obviously help students perform these activities. But why did game-playing experience seem to help students learn about Puget Sound in ways that, superficially, have nothing to do with games or even computers? In seeking to answer this question, it is worth remembering that game-playing is not the same as learning something from a computer. In this study, experience with computer-based learning did not affect performance, whereas game playing did.

\section{References}

Adams, J.A. (1957). Some considerations in the design and use of dynamic flight simulators (AFPTRC-TN D 301.36/6:57-51). San Antonio, TX: Air Force Personnel and Training Research Center.

Alessi, S.M. (1988). Fidelity in the design of instructional simulations. Journal of ComputerBased Instruction, 15, 40-47.

Bayraktar, S. (2002). A meta-analysis of the effectiveness of computer-assisted instruction in science education. Journal of Research on Technology in Education, 34, 173-188.

Blumberg, A.F. \& Mellor, G.L. (1987). A description of a three-dimensional coastal ocean circulation model. In N. Heaps (Ed.), Three-dimensional coastal ocean models. Washington, DC: American Geophysical Union.

Bransford, J.D., Brown, A.L., \& Cocking, R.R. (1999). How people learn: Brain, mind, experience, and school. Washington, DC: National Research Council.

Brown, J.S., Collins, A., \& Duguid, P. (1989). Situated cognition and the culture of learning. Educational Researcher, 18, 32-42.

Bruer, J.T. (1993). The mind's journey from novice to expert. American Educator, 17, $6-46$.

Caird, J.K. (1996). Persistent issues in the application of virtual environment systems to training. Proceedings of the Third Annual Symposium on Human Interaction with Complex Systems. HICS '96, pp. 124-132. Los Alamitos, CA: IEEE.

De Jong, T. \& Van Joolingen, W. (1998). Scientific discovery learning with computer simulations of conceptual domains. Review of Educational Research, 68, 179-201. 
Dede, C., Salzman, M., Loftin, R.B., \& Ash, K. (2000). The design of immersive virtual learning environments: Fostering deep understandings of complex scientific knowledge. In M.J. Jacobson \& R.B. Kozma (Eds.), Innovations in science and mathematics education: Advanced designs for technologies of learning. Mahwah, NJ: Erlbaum.

Dewey, J. (1990). The child and the curriculum. Chicago: University of Chicago Press.

Edelson, D.C. (1998). Realizing authentic science learning through the adaptation of scientific practice. In K. Tobin \& B.J. Fraser (Eds.), International handbook of science education (vol. 1). Dordrecht: Kluwer.

Edelson, D.C., Gordin, D.N., \& Pea, R.D. (1997, March). Creating science learning tools from experts' investigation tools: A design framework. Paper presented at the annual meeting of the National Association for Research in Science Teaching, Oak Brook, IL.

Gordin, D.N. \& Pea, R.D. (1995). Prospects for scientific visualization as an educational technology. The Journal of the Learning Sciences, 4, 249-279.

Kolb, D.A. (1984). Experiential learning: Experience as the source of learning and development. Englewood Cliffs, NJ: Prentice-Hall.

Kolb, D.A., Boyatzis, R.E., \& Mainemelis, C. (2001). Experiential learning theory: Previous research and new directions. In R. Sternberg \& L. Zhang (Eds.), Perspectives on thinking, learning and cognitive styles. Mahwah, NJ: Erlbaum.

Larkin, J.H. \& Simon, H.A. (1987). Why a diagram is (sometimes) worth ten thousand words. Cognitive Science, 11, 65-99.

Lave, J. \& Wenger, E. (1991). Situated learning: Legitimate peripheral participation. Cambridge, UK: Cambridge University Press.

Linn, M.C. \& Muilenburg, L. (1996). Creating lifelong science learners: What models form a firm foundation? Educational Researcher, 25, 18-24.

Linn, M.C., Songer, N.B., \& Eylon, B.-S. (1994). Shifts and convergences in science learning and instruction. The Handbook of Education, 2, 438-490.

Mayer, R.E. (2004). Should there be a three-strikes rule against pure discovery learning? American Psychologist, 59, 14-19.

Meadows, D.H., Meadows, D.L., Rander, J., \& Behrens, W.W. III. (1972). The limits to growth: A report for the Club of Rome's project on the predicament of mankind. New York: Universe Books.

Merrill, M.D. (1992). Constructivism and instructional design. In T. Duffy \& D. Jonassen (Eds.), Constructivism and the technology of instruction: A conversation. Hillsdale, NJ: Erlbaum.

Posner, G.J., Strike, K.A., Hewson, P.W., \& Gertzog, W.A. (1982). Accommodation of scientific conception: Toward a theory of conceptual change. Science Education, 66, 211227.

Price, S. (2002). Animated diagrams: How effective are explicit dynamics for learners? Proceedings of the International Conference of the Learning Societies. Mahwah, NJ: Erlbaum.

Raghavan, K. \& Katz, A. (1989). Smithtown: An intelligent tutoring system. Technological Horizons in Education, 17, 50-53.

Raghavan, K., Sartoris, M.L., \& Glaser, R. (1998). Why does it go up? The impact of the MARS curriculum. Journal of Research in Science Teaching, 35, 547-567.

Resnick, M. (1994). Turtles, termites, and traffic jams: Explorations in massively parallel microworlds. Cambridge, MA: MIT Press.

Rowley, K. \& Meyer, N. (2003-2004). The effect of a computer tutor for writers on student writing achievement. Journal of Educational Computing Research, 29, 169-187.

Ruben, B.D. (1999). Simulations, games and experience-based leaning: The quest for a new paradigm for teaching and learning. Simulation and Gaming, 30, 498-505. 
Scaife, M. \& Rogers, Y. (1996). External cognition: How do graphical representations work? International Journal of Human-Computer Studies, 45, 185-213.

Soderberg, P. \& Price, F. (2003). An examination of problem-based teaching and learning in population genetics and evolution using EVOLVE, a computer simulation. International Journal of Science Education, 25, 35-55.

Steffe, L.P. \& Olive, J. (2002). Design and use of computer tools for interactive mathematical activity (TIMA). Journal of Educational Computing Research, 27, 55-76.

Stott, P.A., Tett, S.F.B., Jones, G.S., Allen, M.R., Mitchell, J.F.B., \& Jenkins, G.J. (2000). External control of 20th century temperature by natural and anthropogenic forcings. Science, 290, 2133-2137.

Stratford, S.J. (1997). A review of computer-based model research in precollege science classrooms. Journal of Computers in Mathematics and Science Teaching, 16, 3-23.

Tanimoto, S., Winn, W.D., \& Akers, D. (2002). A system that supports using student-drawn diagrams to assess comprehension of mathematical formulas. Proceedings of the 2002 International Conference on Theory and Application of Diagrams (Diagrams '02). New York: Springer.

Tversky, B. (2001). Spatial schemas in depictions. In M. Gattis (Ed.), Spatial schemas and abstract thought. Cambridge MA: MIT Press.

Tversky, B., Morrison, J.B., \& Betrancourt, M. (2002). Animation: Can it facilitate? International Journal for Human-Computer Studies, 57, 247-262.

Warner, M.J., Kawase, M., \& Newton, J.A. (2002). Recent studies of the overturning circulation in Hood Canal. Paper presented at the Puget Sound Research Conference, Olympia, WA.

Whitford, D.J. \& Eisman, G.A. (1997). Making science come alive. Journal of College Science Teaching, 27, 109-113.

Windschitl, M. (2000). Supporting the development of science inquiry skills with special classes of software. Educational Technology Research and Development, 48, 81-95.

Windschitl, M. \& André, T. (1998). Using computer simulations to enhance conceptual change: The roles of constructivist instruction and student epistemological beliefs. Journal of Research in Science Teaching, 35, 145-160.

Windschitl, M. \& Winn, W.D. (2000). A virtual environment designed to help students learn science. Proceedings of the International Conference of the Learning Sciences, 2000. Mahwah, NJ: Erlbaum.

Winn, W.D. (1994). Contributions of perceptual and cognitive processes to the comprehension of graphics. In W. Schnotz \& R. Kulhavy (Eds.), Comprehension of graphics (pp. 3-27). Amsterdam: Elsevier.

Winn, W.D., Windschitl, M., Fruland, R.M., \& Lee, Y.-L. (2002). When does immersion in a virtual environment help students construct understanding? Proceedings of the International Conference of the Learning Societies, 2002. Mahwah, NJ: Erlbaum.

Witmer, B.G. \& Singer, M.J. (1998). Measuring presence in virtual environments: “A presence questionnaire," Presence: Teleoperators and Virtual Environments, 7, 225-240.

Zacharia, Z. \& Anderson, O.R. (2003). The effects of an interactive computer-based simulation prior to performing a laboratory inquiry-based experiment on students' conceptual understanding of physics. American Journal of Physics, 71, 618-629.

Zeltzer, D. (1991). Autonomy, interaction and presence. Presence: Teleoperators and Virtual Environments, 1, 127-132. 